\title{
Dali's dimensions
}

Salvador Dali's image of the crucified Christ represents the search for the transcendental or fourth dimension. Artists, theologians, mathematicians and cosmologists down the ages have all joined in the quest.

\section{Martin Kemp}

A recurrent theme of world art has been the striving to reach out into transcendental realms. Any artist so minded inevitably has to confront the paradox that transcendence implies access to dimensions (spatial, material, temporal, conceptual...) beyond those that are open to literal description by the solid surfaces of visible artefacts.

Early in this century, pioneers of modernism in France, Russia and other centres of the avant-garde seized in various ways upon the popularized notions of non-Euclidean geometry, the fourth dimension, infinity and relativity as providing grounds for the rejection of traditional illusions of threedimensional space. The levels of understanding achieved by artists varied greatly, and the general picture is one of opportunistic annexing of new theories in a schematized manner.

One approach, particularly favoured by Russian artists such as Casimir

Malevich and El Lissitzky, was to exploit abstraction as a way of negating conventional space. Malevich's famous Black Square and White on White use extreme reduction of means to evoke the infinity and nothingness that lie beyond material definition, but the effect relies on absence and denial rather than positive visualization.

The dilemma was not one exclusive to artists. All the ingenious attempts by mathematicians and cosmologists to provide visual tools for the concrete envisaging of the fourth dimension have struggled with the irredeemably three-dimensional parameters of the sensate space beyond our bodies and within our minds - and with the limited representational techniques available to us.

The kinds of diagrammatic solutions proposed at the end of the last century by the eccentric mathematician and convicted bigamist, Charles Howard Hinton, seem to be about the best we can do. His unfolded four-dimensional hypercube or tesseract as the spatial counterpart of a normal cube that has been unfolded into a flat templatebecame a popular and mystical symbol of the transcendent spaces of the new mathematics.

As such it was adopted by the renowned Spanish Surrealist, Salvador Dali, in his Corpus (or Christus) Hypercubus, in which Christ's sacramental body is transfixed ambiguously within the foremost of the cubes of a Hintonian tesseract, floating in front of the Virgin above a pavement decorated with an unfolded $3 \mathrm{D}$ cube.

Is this more than slick visual opportunism or, at best, knowing symbolic allusion? We may gain some comfort from learning that Thomas Banchoff, the author of Beyond the Third Dimension (W. H. Freeman, 1990), had been contacted by the artist and was impressed by his "technical knowledge”. Yet doubts remain. Dali was not working visually with anything beyond standard cues for the representation of forms in space.

However, in our present context, Dali's painting does stand effectively for an age-old striving in art, theology, mathematics and cosmology for access to those dimensions that lie beyond the visual and tactile scope of the finite spaces of up-and-down, left-andright, and in-and-out that imprison our common-sense perceptions of our physical world. The scientists' success in colonizing the extra dimensions is defined mathematically. The artists - and Dali's corporeal Christ - reach out by visual inference.

Martin Kemp is in the Department of the History of Art, University of Oxford, 35 Beaumont Street, Oxford OX1 2PG, UK.

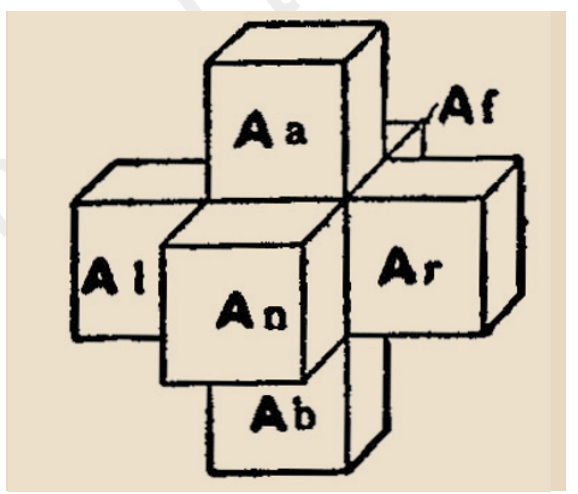

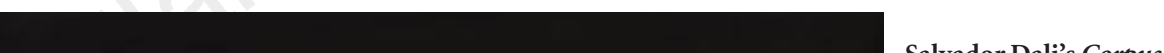

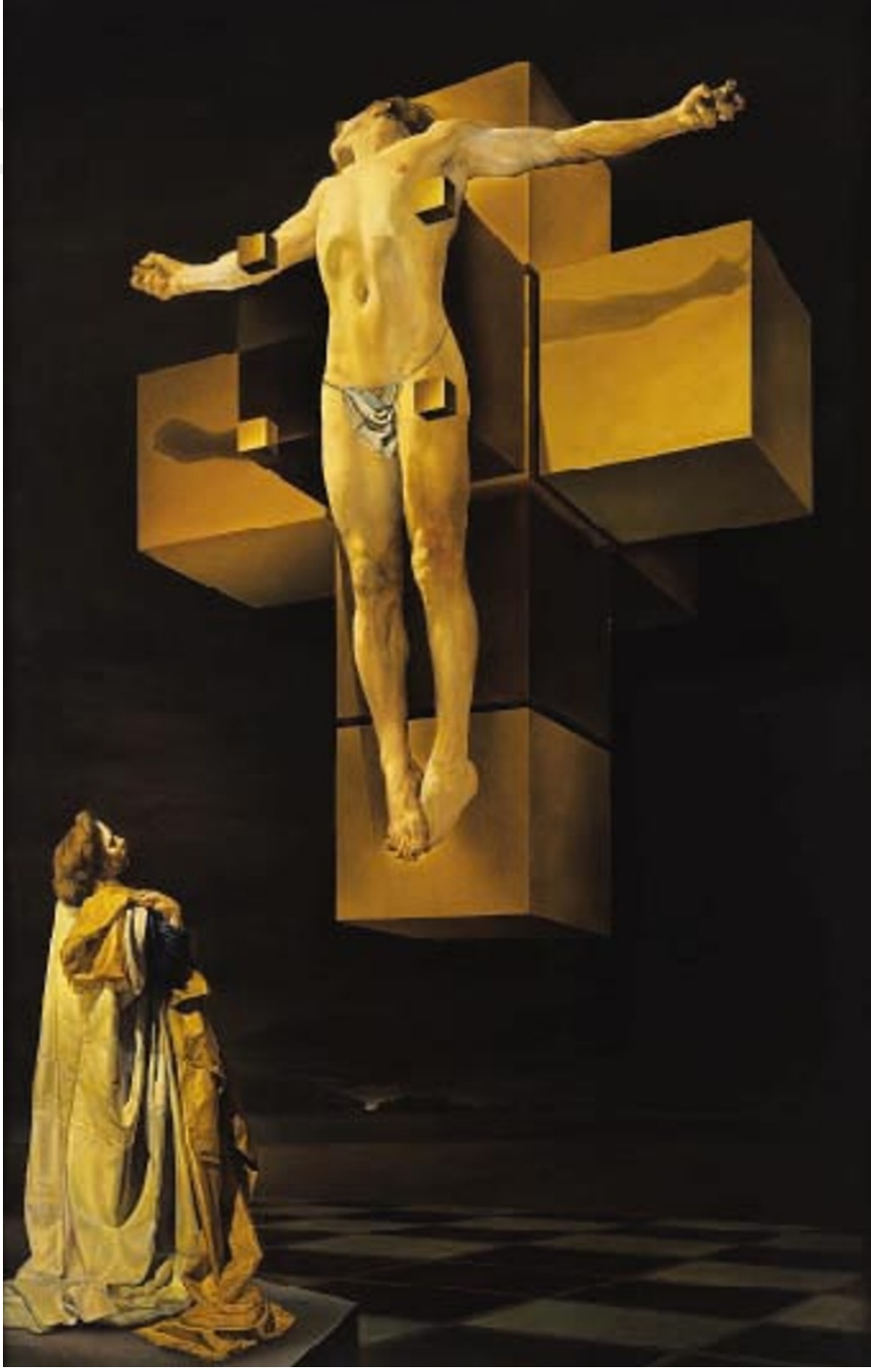

Hypercubus (Crucifixion), 1954, and (above) the hypercube of Charles Howard Hinton, from his book The Fourth Dimension, 1912. 